\title{
SENDEROS PARALELOS Y ATAJOS OBLICUOS
}

\section{Ariel Gravano $^{1}$}

\section{Individuo social: memorias, olvidos y preguntas}

Las antropólogas y los antropólogos hemos aprendido e intentamos enseñar que el individuo humano (como humano, propiamente: creador de cultura en sociedad) no existe. Que, en todo caso, lo individual y su correlato, la categoría de individuo, es una representación históricamente construida y enmarcada por lo social - por la sociabilidad - y por lo cultural, por los valores, representaciones y prácticas compartidas y en contradicción permanente, y compuesto principalmente por la relación dialéctica entre lo reproducido (mediante la memoria social) y lo olvidado (esto es: entre lo que objetivamente pasó pero subjetivamente no fue registrado), de acuerdo con intereses y racionalidades determinados social e históricamente.

Hemos aprendido y enseñamos que en muchas sociedades (principalmente las estudiadas por los antropólogos en su trabajo más clásico) no predomina la imagen del individuo sino mucho más la del grupo, el clan, o el pueblo. Y esta constatación es mayor si la establecemos como contraste con la imagen del individuo de la modernidad occidental.

Pero a pesar de eso, partimos de la creencia de que eso somos: individuos, aunque sepamos que construidos social y culturalmente: dentro de procesos que nos determinan, que impulsan y restringen nuestros sentidos y significados, nuestros recuerdos y olvidos, nuestra conciencia y no-conciencia.

$\mathrm{Y}$ entonces aquí estoy, rindiendo en forma individual alguna cuenta con mi propia trayectoria como antropólogo. Cuenta que - como se verá - tiene mucho más de "pendiente" que de resultados y méritos, mucho más en el debe que en el haber.

Es un gusto y una alegría compartir con ustedes esta invitación de las amigas y entrañables trabajadoras Cornelia Eckert y Ana Luiza Carvalho da Rocha, que tendrán alguna razón y expectativa para haberla hecho, y que espero satisfacer, no tanto en forma individual, entonces, sino "con" todos ustedes. Trataré de recordar (seguramente a la par de olvidar), sociabilizando con ustedes mi propia memoria, en forma acorde con los propósitos temáticos del Coloquio.

\footnotetext{
${ }^{1}$ Universidad de Buenos Aires, Argentina.
} 


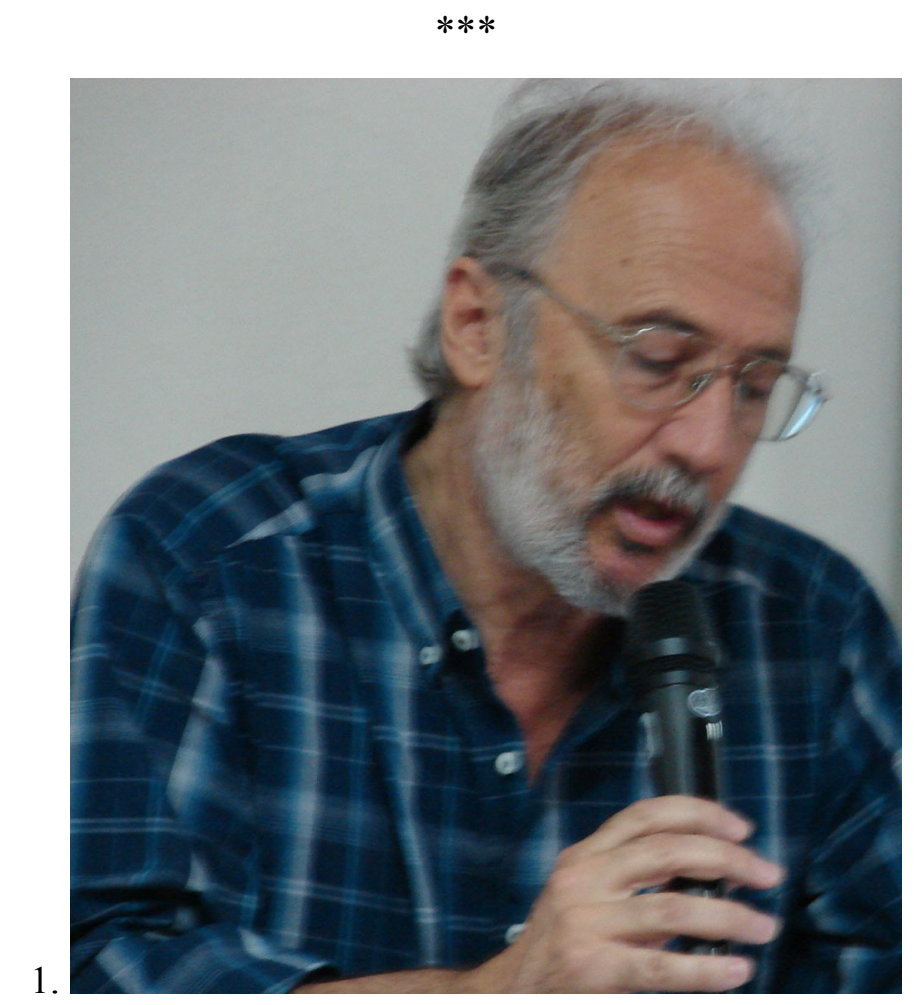

Prof. Ariel Gravano. Foto de 02 dezembro 2010. II Colóquio Individualismo, Sociabilidade e Memória. Acervo BIEV PPGAS IFCH UFRGS.

Por lo tanto, empezaré por algunas preguntas que articulan mi trabajo actual y las relacionaré luego con el contexto histórico-biográfico.

¿Cómo colaborar con efectividad para producir las rupturas prácticas y simbólicas más necesarias en los modos que tenemos de hacer las cosas dentro de procesos que permitan orientar el mundo en que vivimos hacia sociedades realmente justas e igualitarias, esto es: sin explotación?

¿De qué manera este propósito puede articularse con la producción de conocimiento antropológico propio y de la disciplina en su diversidad de enfoques, sin necesidad de colocar la tarea profesional como algo paralelo a la colaboración con el cambio?

¿Cómo articular dialécticamente este aporte profesional desde la investigación y la facilitación de procesos concretos?

\section{Trabajos de entrecruces}

Mis actividades y proyectos actuales - junto a un talentoso grupo de colegas- apuntan a estos interrogantes y propósitos en un abigarrado entrecruce hacia un objeto complejo. El proyecto en vigencia se llama Imaginarios urbanos, gestión y participación social: procesos 
de construcción de alternidades organizacionales en escalas barrial, en ciudades de rango medio y ámbitos metropolitanos. Tiene por objetivo estudiar la relación entre los imaginarios sociales urbanos con la cultura organizacional de procesos participativos asociados a la planificación y diseño urbano y la gestión de servicios públicos, incluyendo las posibilidades de registro y facilitación de alternidades, entendidas éstas como opciones de transformación no sólo de realidades sociales sino también de los modos de gestión institucional para lograr esas transformaciones.

El problema que se aborda abarca principalmente la ponderación de los imaginarios como un objeto de estudio no tradicional para instancias de planeamiento y gestión urbana, donde en la mayoría de los casos no se lo tiene en cuenta o bien entra en el terreno de los supuestos pre-disciplinares. En casos de demandas explícitas, nuestro objeto incluye la problematización de esa demanda, en términos de los sentidos culturales desde el punto de vista organizacional con que se gestionan socialmente esos mismos procesos. Así, de la investigación pasamos a la facilitación en términos de aportes metodológicos a la mejora o transformación, de acuerdo con las perspectivas que los actores destinadores y destinatarios van intercambiando en relaciones de poder institucional determinadas, para las cuales la otredad cultural (como objeto antropológico) se constituye en clave de la circularidad de la gestión.

Coloco como "cuenta pendiente" la publicación de los resultados definitivos de este proceso. Por un lado, porque es reciente la objetivación que estamos desarrollando. Por otro, porque el sistema científico-tecnológico-académico argentino no da suficientes posibilidades de desarrollar esta línea en cuanto a la formación de equipos, ya que, o bien se prioriza la separación entre investigación académica e intervención profesional, o bien a ésta última la Antropología no la tiene en cuenta como parte de su perfil de incumbencias. Y esto lo verifico en el sistema de evaluaciones, presentaciones a proyectos, post-graduaciones, etc.

Además, la no publicación quizá tenga que ver con esta última razón - en cuanto a la no comprensión del sistema de Ciencia y Técnica de lo que es la facilitación organizacional, pero también puede deberse a lo que me dijo un arquitecto urbanista con quien trabajé como facilitador de un proceso participativo de planificación urbana (que en parte fue publicado con gran generosidad en la revista Horizontes): "si vos contás todo lo que hacés, lo más probable es que no te llamen para facilitar". Y me lo dijo cuando concurrió a un seminario en el IDES, donde algunos colegas discutían ese trabajo. Quizá tampoco sea casual que ninguno de esos 
trabajos haya sido publicado en mi país: en el fondo puede ser que yo no quiera decir todo lo que hago, para que me llamen...

\section{Entre senderos paralelos y atajos oblicuos}

Pero ¿cómo empezó esto?

Diría que con mi propio extrañamiento, como parte de las capas medias urbanas en Argentina, ante lo popular-folklórico-indígena de la década del sesenta.

Fue la época donde muchos jóvenes de las grandes ciudades aprendimos que existía un país Otro, el que venía del interior de un territorio cultural olvidado por la "jaula de acero". Y esto lo aprendimos (lo aprendí) cantando. Aprendiendo y compartiendo un repertorio de altísima calidad estética proveniente de grandes poetas y músicos de las provincias argentinas. A esto se lo llamaba "folklore". Y al "descubrimiento" que las grandes ciudades hicieron se lo llamó el "boom del folklore de los sesenta". Grandes migraciones internas desde varias décadas atrás habían producido en parte esta necesidad de construir un "nosotros" nacional a partir de las "otredades" culturales. Y los medios de difusión masiva se vieron "invadidos" de estos mensajes, catalogados - etnocéntricamente - de "regionales".

Fui uno más de ese contingente de jóvenes, en un contexto histórico argentino, latinoamericano y mundial caracterizado por los efectos de la derrota del fascismo en Europa, la creciente alternativa del campo socialista como Segundo Mundo ante el Primer Mundo imperial (cuyo hito continental era la Revolución Cubana), las luchas anticolonialistas y antiimperialistas en el llamado Tercer Mundo (cuyo hito fue la guerra de liberación de Vietnam) y la eclosión cultural del movimiento juvenil como actor preponderante del momento. Aprendimos la otredad desde el interior y desde el exterior. Aprendimos, como capa social media, a "descubrir" las luchas de nuestro propio pueblo, de sus ocultas "raíces" ancestrales e indígenas, sus pertenencias a imaginarios "otros" y a una conciencia social diversa y en ebullición. Incluso re-valoramos historias culturales familiares. Aprendimos a leer grandes poetas y a construir - en algunos casos a practicar - y sumarnos a un imaginario de libertad, de transformación, de lucha.

Y por esto de la otredad entro a la carrera de Ciencias Antropológicas de la Universidad de Buenos Aires, casi a tientas en el fervor de lo que se vivía, a mediados de los años sesenta. Me recibe una Universidad golpeada por los bastones de la dictadura del general Onganía, en 1966, y la efectiva aplicación de la doctrina de la seguridad nacional, que colocaba como enemigo de la patria al propio pueblo, como ocurrió en tantos países de 
nuestro continente. El "mundo libre" iniciaba sus intentos de restauración capitalista y no perdonaría la eventual repetición del triunfo revolucionario cubano, hasta producir incluso las atrocidades que todos conocemos.

Comencé, como le pasó a muchos, dos carreras: una, la oficial, la de la universidad, para la cual baste decir que la Antropología Social no existía. Recién hacia fines de los sesenta aparece una materia con ese nombre, en la que el gran descubrimiento era Durkheim y - como solía ocurrir - el marxismo estaba ausente o nunca se lo llegaba a poder incluir en el programa por razones de tiempo...

Para muchos estudiantes de esa época, el antídoto eran las lecturas de tiempo libre sobre todo para la mayoría, que estudiaba y a la par trabajaba. A mí me interesaba personalmente la cultura popular. En las materias donde se enseñaba Folklore, los autores marxistas tampoco existían, ni siquiera para refutarlos. Predominaba en la Antropología el enfoque histórico-cultural fenomenológico y en Folklore el funcionalismo, ambos esencialistas. Unos estudiaban a las poblaciones aborígenes y otros a las "tradicionales", con esa mirada congeladora de la historia y las contradicciones, que fue lo que produjo por mucho tiempo la estigmatización de esos “objetos” por parte de la Antropología Social en Argentina².

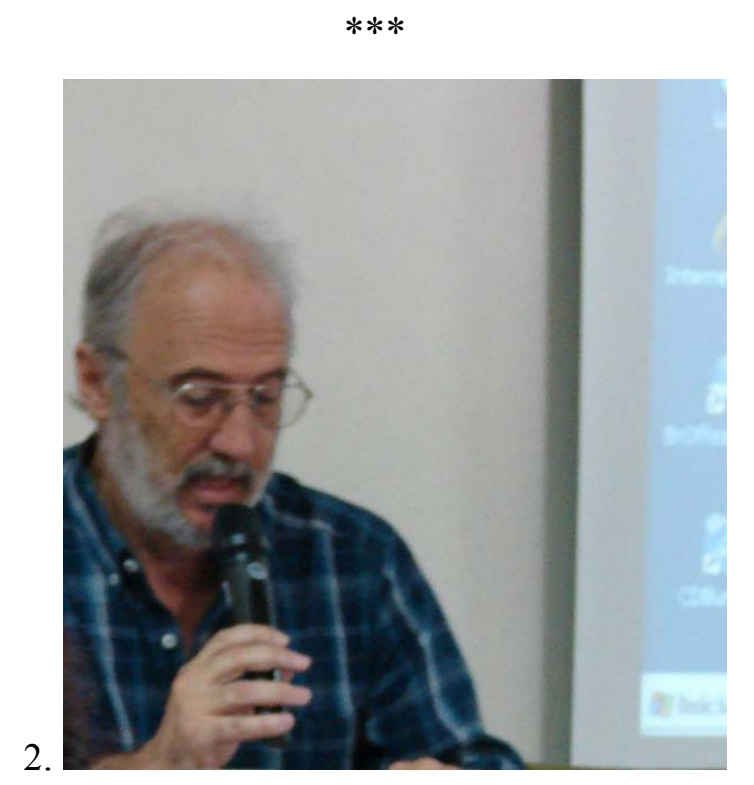

Prof. Ariel Gravano. Foto de 02 dezembro 2010. II Colóquio Individualismo, Sociabilidade e Memoria. Acervo BIEV PPGAS IFCH UFRGS.

$$
* * *
$$

Aprendí, en paralelo a la carrera, a tener otra mirada del mundo tradicional y popular, junto a autores de mi país como Luis Gudiño Kramer, Bernardo Canal-Feijóo, Marcelino

\footnotetext{
${ }^{2}$ Para quien se interese por la historia de la Antropología en Argentina son importantes los aportes de Edgardo Garbulsky, Carlos Herrán, Hugo Ratier, Rosana Guber, entre otros (ver Bibliografía).
} 
Román. Luego con Gramsci, Vladimir Propp, Mijáil Bajtín, Voloshinov, se me abrieron cauces desde los cuales pude ir contrastando con los marcos funcionalistas y culturalistas. Me auto-formé en enfoques semióticos de la cultura. Parte de esto volqué en trabajos que también fui haciendo en forma paralela y que algunos años después pude publicar. Comencé a pensar que podía realizar mis tesis de grado y posgrado con estas temáticas. En la primera instancia tuve más suerte que en la segunda. Publiqué mi libro El silencio y la porfía, sobre la música popular argentina, luego de lograr la Licenciatura. Cuando me dispuse a trabajar de antropólogo, la enésima dictadura cerró directamente la Carrera (el silenciamiento no sólo se ejercía ante la canción popular). Desde el Colegio de Graduados en Antropología nos opusimos y logramos que se reabriera. Pero conseguir trabajo como investigador o docente me resultó imposible. Algún profesor de aquella época me llegó a llamar "El Rojo", simplemente porque no era funcionalista o culturalista, tendencias que supuestamente tenían otro color. Así y todo, no me tocó sufrir las persecuciones de otros colegas, detenidos, perseguidos o desaparecidos ${ }^{3}$.

Baste decir que en aquella época (sobre todo entre 1976 y 1983), en algunos ámbitos intelectuales, decir "antropólogo social" implicaba una acusación, algo así como decir "subversivo", con todas sus consecuencias.

Junto a esto, me tocaron vivir algunas situaciones, que sigo creyendo hoy "me pasaban a mí", aunque debería pensar que eran el resultado de debates más amplios y compartidos. Pero reconozco no haber reflexionado sobre ello hasta ahora.

Por ejemplo, algunos colegas amigos, incipientes antropólogos sociales y de orientación marxista, recelaban estudiar a las poblaciones indígenas porque habían sido “cosificadas" por los enfoques predominantemente fenomenológicos ahistóricos. Y también renegaban y hasta negaban la existencia del Folklore y la cultura popular como objeto de estudio, por considerar que eso significaba también enfocarlos desde una mirada conservadora y reaccionaria.

Otros colegas, más de orientación nacionalista y militantes peronistas, acordaban conmigo en la necesidad de investigar el mundo popular, pero no acordaban con el enfoque

\footnotetext{
${ }^{3}$ En el I Congreso de Folklore Iberoamericano, en Santiago del Estero, en 1980, e invocando que yo no pertenecía a la "línea" de estudios predominante en Argentina, la presidente de ese congreso pretendió burdamente meterme preso, cosa que impidieron algunos colegas cuando se enteraron. Fue por "temor" a que yo manifestara esa "no pertenencia" ante la presencia de un general del Ejército que - por ser coterráneo de la provincia donde se realizaba iba a visitar el Congreso. Cuando hizo su aparición, súbitamente se interrumpió el debate de una ponencia para que subiera al estrado otra congresista que ya había expuesto su trabajo, de modo que el general de marras no presenciara ningún debate.
} 
marxista, por considerarlo "europeo" y reivindicaban a lo popular exclusivamente asociado a lo nacional.

Esto tendría importancia al encarar finalmente mi profesionalización como investigador. En principio, luego de licenciarme pude publicar en México, Venezuela y Argentina. Y trabajé cinco años en lo que iba a ser una tesis de doctorado sobre la canción popular de temática social en Argentina.

Cuando me iba a presentar para ingresar al sistema científico, ya en plena apertura democrática, una colega me sugirió que no lo hiciera con una temática de cultura popular y mucho menos de Folklore, pues seguramente no iba a ser bien evaluado, ya que eso se consideraba reaccionario, un resabio de las posiciones conservadoras y pro-dictadura en la Antropología argentina. Como mi intención era realizar ese ingreso y vivir de mi profesión, construí un objeto que tuviera que ver con lo urbano, de manera de encubrir mis más aviesas intenciones de dedicarme a lo popular. El barrio y la realidad barrial resultarían ser parte de esa alternativa o estrategia de reproducción profesional, o de mera supervivencia.

En forma paralela, que parece ser una constante en mi trayectoria, me pude formar como antropólogo en lo que considero una segunda carrera, al tener acceso a colegas de los cuales aprendí acerca de la Antropología en general y lo metodológico en particular. Me refiero a la cercanía con mi amigo y compañero Edgardo Garbulsky, el vínculo con mi director de tesis Carlos Herrán y a la vinculación con la cátedra de Antropología, del Ciclo Básico Común de la UBA, de Mirta Lischetti (con gran influencia de la obra de Eduardo Menéndez), de la cual en la actualidad ejerzo la conducción, y un trayecto breve pero clave por la cátedra de Metodología y Técnicas de Trabajo de Campo, de Ester Hermitte y Rosana Guber, en la que más que enseñar aprendí a "hacer etnografía”.

Esto se condensó en la publicación del trabajo "La imaginación antropológica; interpelaciones a la otredad construida y al método antropológico", en la revista Publicar en Antropología y Ciencias Sociales, en 1995, revista afortunadamente reaparecida en la actualidad, y de la cual he traído ejemplares para los colegas presentes. Ahí comienza a desarrollarse la idea de una Antropología como servicio profesional interdisciplinario desde una especificidad disciplinar.

Inserto ya en el sistema de Ciencia y Técnica, pude culminar mi doctorado, que cristalicé en dos libros: Antropología de lo barrial: un estudio sobre producción simbólica de la vida urbana, y El barrio en la teoría social. Algunas de las repercusiones de este trabajo fueron los pedidos de dictado de seminarios de post-grado en distintas universidades, 
incluyendo visitas a Uruguay, Bolivia, Chile, Guatemala, El Salvador, Costa Rica y creo que también ésta, a Brasil.

\section{Antropología de lo barrial ${ }^{4}$}

En mi análisis antropológico de lo barrial, tomando como base las vacancias sobre los enfoques simbólicos de la vida en los barrios, he intentado diseñar un modelo de comprensión apuntando a lo que podía haber "detrás" de lo barrial como símbolo, y determinar los mecanismos semióticos que se ponían en marcha en esa construcción de sentido. A su vez, establecí hipótesis sobre las razones históricas de esas construcciones ideológico-simbólicas y de las identidades referenciadas en el espacio barrial.

En la Región Metropolitana de Buenos Aires, mostré el proceso que estructura el surgimiento de los barrios como una necesidad de la expansión urbana y que configura las realidades barriales como identidades típicas, morfológica, social y culturalmente, a partir de la diferenciación, por un lado, entre el centro de la ciudad y los barrios y, por el otro, entre los mismos barrios. La historia de la región tiene en este horizonte simbólico el parámetro desde donde se estatuyen en el imaginario los inventarios de "pérdidas", signo que finalmente aparece tiñendo el escenario barrial.

Y esa historia encuentra que el barrio ocupa un lugar de importancia como síntoma de una crisis que se presenta a veces como resultado del choque de lo típico y tradicional contra el "progreso", y que desde nuestra visión teórica definimos en términos de dependencia, privatización y expoliación de los espacios urbanos, entre ellos, el barrial.

La realidad objetiva ante la cual esa producción simbólica actúa con eficacia es el no control de ciertas condiciones de vida propias de sus actores, lo que sería correspondiente con el proceso asimétrico de apropiación continua del excedente urbano. Y encuentra correspondencia mediada en el nivel de las representaciones, cuando la no participación en el "adelanto" o "progreso" histórico se corporiza ideológicamente en el control o no de los servicios urbanos dentro del barrio y se representa como una desvalorización de esos servicios y de ese "adelanto" impuesto, no propio.

En el futuro del ideal de vida, en el pasado deshistorizado y en las identidades construidas en el contradecir histórico, siempre el barrio tiene el significado de oponerse a algo (a la ciudad en su conjunto, al centro, a otro u otros barrios) por medio de la atribución / negación de un conjunto de valores que conforman lo barrial.

\footnotetext{
${ }^{4}$ Reproduzco aquí parte de mis conclusiones publicadas en Antropología de lo barrial (Edit. Espacio, Buenos Aires, 2003).
} 
Convalido la vigencia de este modelo de lo barrial como un horizonte simbólico recurrente y socialmente diseminado, pero más presente en los barrios populares.

Lo barrial como cultura es la producción de sentido que se referencia en el espacio, la identidad, la ideología y las prácticas barriales y que adquiere significación histórica dentro de la dialéctica entre la ruptura con lo dado o naturalizado respecto de la realidad de sus actores. Cultura como metáfora social capaz de modelizar comportamientos y representaciones.

Pero no una cultura como "modo de vida", al estilo antropológico clásico, y menos como la ha enfocado el culturalismo ahistórico, y tampoco como mera adición decorativa sobre lo estructural-material, sino como un horizonte simbólico subyacente en una gran diversidad de contextos, capaz de reproducir, operar e historizar la vida. Con esta postura se articula nuestro interés por no segmentar mecánicamente la producción de sentidos y ver a la cultura barrial en circulación y no en instancias estáticas. Lo que nos obliga a encuadrarla dentro de las contradicciones principales y secundarias de la sociedad que se trate, y de necesaria ponderación de sus sectores sociales más importantes (clases sociales), desde su posición en la estructura socio-económica, como elemento contradictorio "previo" a todo conflicto manifiesto. Expropiaciones y asimetrías socio-urbanas concretas que configuran quiénes controlan y quiénes no controlan, quiénes son expropiados y quiénes dominantes, quiénes hegemónicos y quiénes subalternos (aún en los términos relativos y dialécticos con que se conformen estas relaciones de oposición).

El concepto de subalternidad nos deriva hacia lo popular, pero no desde una sectorización mecánica (a la manera de la sociología funcionalista), sino desde el interior de los procesos estructurales, históricos y semióticos. Fue Antonio Gramsci el que definió a lo popular como lo subalterno, para romper precisamente con el idealismo romántico, superficial y esencialista del Folklore. Con Mijail Bajtín, podemos extender este sentido de lo popular para verlo en circulación comunicacional, como sistema de imágenes y formas expresivas, no sólo contenidos, de ahí la importancia de descifrar interpretativamente las imágenes y los significados en contexto, para descubrir qué es lo que sustituyen y simbolizan. Así, lo popular - como producto histórico - resulta trascendente a cualquier cosificación de supuestos sectores estancos.

¿Qué elemento podemos sumar a la hipótesis del no control para estipular las razones históricas de existencia y constitución de lo barrial como cultura popular? La posibilidad de que la cultura barrial sea o pueda ser tanto subalterna como alterna a la estructuración dominante de la sociedad contemporánea. 
Carlos Marx concebía a la cultura popular como no explicable por su correspondencia mecánica con la base material de la sociedad ni por sus contenidos, ni tampoco por el modelo dominante, sino por su significación dentro de situaciones concretas, sobre la base del avance o no que produce en la conciencia social de los pueblos. Y la consideraba como una producción propia, no degradada ni decadente (Gravano, 1988). Gramsci seguirá esta línea al fundamentar el concepto de hegemonía argumentando que lo dominante "no se desarrolla sobre la nada", sino en contradicción con lo popular, para combatirlo y vencerlo (Gramsci, 1975:329).

En estas investigaciones lo popular se asociaba a lo barrial como connotación o en términos metonímicos, en las emergencias de la noción de barrio en el sentido común y los discursos públicos. Aparecía como escenario de residencia de las clases populares, como parte física de la reproducción de la fuerza de trabajo de las ciudades a lo largo de la Historia. Pero, si bien lo barrial se patentiza más en los barrios "populares", ostenta su diseminación por el resto de espacios sociales no populares, incluso a pesar de la "crisis de valores" que promueve la imagen del barrio como modo de vida en extinción.

Las situaciones de ritualidad barrial vigentes en contextos convencionalmente no populares muestran que lo barrial, como cultura, trasciende la sectorización social empírica rígida y a la vez nos sirve para recuparar algunos de los planteos clásicos, como el de Park o el de Lynch, sobre el para quién y el de quién del barrio.

Planteamos que lo popular no debe acotarse a criterios empírico-estadísticomecanicistas o funcionalistas para su definición y sí por medio de su contextualización histórico-estructural en torno a la dialéctica de la oposición social fundamental. Edward P. Thompson afirma que los sujetos sociales se constituyen a partir de un conflicto social que les es previo (Thompson, 1978). En nuestro caso, es posible relacionar lo popular ligado a la cultura barrial si se trasciende la empiria hacia la concepción bajtitiana de lo barrial en circulación, irradiado y diseminado desigualmente en el conjunto social.

Esta línea nos alerta respecto a la reificación del eje de la subalternidad para definir lo popular como la postulación de la conciencia del conflicto en la conceptualización de Néstor García Canclini (1982). En efecto, el interrogante que nos planteamos es si con el concepto de subalternidad - como eje exclusivo - no se propende a ponderar sólo el carácter reproductor de la realidad de los sectores populares y un estado histórico y, por lo tanto, transitorio de sus relaciones sociales, precisamente la que impone concebirlos como subalternos. ¿Es posible preguntamos - dar cuenta del flanco transformador, progresivo, rupturista y (potencial o 
realmente) revolucionario de esos mismos sectores en sus manifestaciones culturales e ideológicas en su vida cotidiana? ¿No es necesario para esto concebir que si los sectores populares son subalternos es porque, en términos estructurales, antes son alternos $\mathrm{y}$, en términos históricos, pueden realmente serlo?

¿No podemos afirmar que sólo si se los concibe como fuerza contraria a los agentes dominantes se podrá concebir que éstos necesiten operar hacia ellos para "construirlos" precisamente como subalternos? ¿No es necesario explicitar que el ejercicio de la hegemonía es concebible como históricamente necesario sólo si se concibe en forma concreta la posibilidad de que estos sectores populares dejen de ser subalternos?

Así, lo barrial como cultura no tiene un valor unívoco ni adherido a lo empírico en forma directa y determinante, sino simbólico, tan transformador como reproductor, tan historizador como deshistorizador. Tiene el sentido de lo incompleto y en renovación permanente. Su sentido de lo renovador se asume como lo crítico, impugnador y contrario a la estabilidad y el orden formales, institucionales y hegemónicos.

Detrás del "control" simbólico que ejerce lo barrial constituido en cultura y manipulado como ideología desde el sentido común, se dirime la puja por el control efectivo de las propias condiciones de vida de los sujetos sociales, lo que explica, además, que lo barrial no sea tan "necesario" en los sectores que más controlan parte de su condiciones de vida urbana.

\section{Antropología de los imaginarios urbanos}

En forma paralela a mi obtención del cargo de profesor titular ordinario de la materia Antropología Urbana en la Universidad Nacional del Centro de la Provincia de Buenos Aires, en la ciudad de Olavarría, se escalonaron demandas de urbanistas y arquitectos, en torno a la temática de los imaginarios urbanos y su ponderación como objeto antropológico. En esos casos intenté también producir esas demandas en los agentes vinculados con la gestión urbana, ya que el objeto de estos trabajos era la detección de los significados con que los actores sociales viven el espacio, además de vivir en el espacio. 
Desarrollamos una línea específica sobre el estudio de los imaginarios de la ciudad de rango medio, que se plasmó en el libro Imaginarios Sociales de la Ciudad Media, emblemas, fragmentaciones $y$ otredades urbanas, de 2005. Y en la actualidad se proyecta hacia investigaciones en las ciudades de Mar del Plata, Olavarría, Tandil, Campana, Montevideo y Buenos Aires.

\section{Antropología organizacional para la gestión}

Desde hacía ya varios años, en forma paralela a mis trabajos de investigación (y hoy en forma articulada), comencé a desarrollar una línea de Antropología Organizacional, sobre la base de las demandas concretas de los actores con quienes los antropólogos estamos acostumbrados a actuar y con quienes a mí en particular me interesó focalizar mi labor profesional de servicio. La demanda consistía en mejorar su gestión social ante desafíos organizacionales. Dicha inquietud, fundada teórica, metodológica y casuísticamente, la sistematicé en un trabajo que titulé "Antropología Práctica: muestra y posibilidades de Antropología Organizacional" (1992) y, luego de su articulación con la investigación, la plasmé en algunos trabajos de los últimos años. Pero está pendiente su mayor sistematización. Es una de las vertientes para responder a los interrogantes que enuncié al principio de esta comunicación acerca de los modos del hacer y la participación.

En síntesis, lo que he tratado de reflejar es un camino profesional con senderos paralelos y atajos oblicuos, recuerdos y olvidos, no siempre inconscientes. Siempre ante el desafío de articular el desarrollo individual, desde donde creo que soy lo que hice, y la trama social, desde la que indiscutiblemente me he constituido profesional y personalmente, con las contradicciones propias y paradojas ante las que me sitúo y las que he producido, a veces en forma planificada y muchas en forma inesperada, como esta misma invitación ante la cual no puedo más que sentirme halagado y sobre todo agradecido.

\section{Referências}

ACTUALIDAD ANTROPOLÓGICA. Antropología Social, aquí y ahora, 1-3. Olavarría, Provincia de Buenos Aires: Museo Dámaso Arce, 1968.

COLEGIO DE GRADUADOS EN CIENCIAS ANTROPOLÓGICAS. Jornadas de Antropología: 30 años de la carrera en Buenos Aires (1958-1988). Buenos Aires: Facultad de Filosofía y Letras/UBA, 1989.

FÍGOLI, L. "A antropologia na Argentina e a construção da nação". En: CARDOSO DE OLIVEIRA, R. \& RUBEN, G. R. (org.). Estilos de Antropologia. Campinas: Editora da Unicamp, 1995. 
GARBULSKY, E. "La antropología social en la Argentina". En: Runa, 20, Buenos Aires: Instituto de Ciencias Antropológicas -ICA/Facultad de Filosofía y Letras/ UBA, 1991. pp. $11-34$.

GARBULSKY, E. "La antropología argentina en su historia y perspectivas. El tratamiento de la diversidad, desde la negación / omisión a la opción emancipadora". En: I Jornadas Experiencias de la Diversidad. Rosario: Universidad Nacional de Rosario/ Centro de Estudios sobre Diversidad Cultural, Facultad de Humanidades y Artes, 9 y 10 de mayo de 2003.

García Canclini, N. 1982: Las Culturas Populares en el capitalismo. Nueva Imagen, México. GRAMSCI, A. "Observaciones sobre el Folklore". En: Cultura y Literatura. Barcelona: Península, 1975. p. 329-336.

GRAVANO, A. El silencio y la porfía. Buenos Aires: Corregidor, 1985.

GRAVANO, A. "Ideología, cultura popular y formulación clásica del Folklore". En: Revista de Investigaciones Folklóricas, 2. Buenos Aires: Fac. Fil. y Letras/UBA, 1988. p. 40-44.

GRAVANO, A. "Antropología Práctica, muestra y posibilidades de la Antropología Organizacional". En: Publicar en Antropología y Ciencias Sociales, 1. Buenos Aires: Colegio de Graduados en Antropología de la República Argentina, 1992. p. 95-126.

GRAVANO, A. "La imaginación antropológica; interpelaciones a la otredad construida y al método antropológico". En: Publicar en Antropología y Ciencias Sociales, 5. Buenos Aires: Colegio de Graduados en Antropología de la República Argentina, 1995. p. 71-91.

GRAVANO, A. Antropología de lo barrial, estudios sobre producción simbólica de la vida urbana. Buenos Aires: Espacio Editorial, 2003.

GRAVANO, A. El barrio en la teoría social. Buenos Aires: Espacio Editorial, 2005.

GRAVANO, A. (compil.). Imaginarios de la ciudad media: emblemas, fragmentaciones y otredades urbanas, estudios de Antropología Urbana. FACSO y SCYT de la UNICEN: Consejo Editor de la UNICEN, 2005.

GRAVANO, A. "La proyección del enfoque etnográfico hacia la facilitación organizacional en procesos participativos de planificación urbana". En: Horizontes Antropológicos, v. 15, n. 32; July/Dec. Porto Alegre: PPGAS/IFCH/UFRGS, 2009. p. 81-114.

GUBER, R. “'Antropología Social': una categoría nativa de la diáspora antropológica argentina". En: Anuário Antropológico 2000/2001. Rio de Janeiro: Tempo Brasileiro, 2003.

GUBER, R. "Linajes ocultos en los orígenes de la antropología social de Buenos Aires". En: Avá, n. 8, Posadas: PPAS-UNaM/CONICET/Antropofagia, 2006. p. 26-56.

GUBER, R. \& VISACOVSKY, S. "La antropología social en la Argentina de los '60 y '70. Nación, marginalidad crítica y el «otro» interno". En: Desarrollo Económico, v. 40, n. 158. Buenos Aires: Instituto de Desarrollo Económico y Social, 2000. p. 289-316.

HERRÁN, C. "Antropología Social en la Argentina: apuntes y perspectivas". En: Cuadernos de Antropología Social, v.2, n.2. Instituto de Ciencias Antropológicas. Sección Antropología Social. Facultad de Filosofía y Letras. Buenos Aires: UBA, 1990. p.108-115.

HERMITTE, E. "Informe sobre el estado actual de la Antropología Social en la Argentina". En: MARSAL, Juan (Coord.). Las ciencias sociales en la Argentina. Buenos Aires: Instituto Di Tella, 1968.

RATIER, H. La antropología social argentina: su desarrollo. En: Publicar en Antropología y Ciencias Sociales, IX, año VIII. Buenos Aires: Colegio de Graduados en Antropología de la República Argentina, 2010. p. 17-48.

RATIER, Hugo E. y RINGUELET, Roberto. La antropología social en la Argentina: un producto de la democracia. En: Horizontes Antropológicos, ano 3, n. 7, Porto Alegre: PPGAS/IFCH/UFRGS, 1997. p. 10-23. 
VISACOVSKY, S. \& GUBER, R. (comps.). Historias y estilos de trabajo de campo en Argentina. Buenos Aires: Editorial Antropofagia, 2002.

THOMPSON, E. Tradición, revuelta y conciencia de clase. Madrid: Cátedra, 1978.

Recebido em: 20/12/2010

Aprovado em: 28/03/2011 